Gut, 1988, 29, 1725-1729

Techniques

\title{
Determination of total gastric volume, gastric secretion and residual meal using the double sampling technique of George
}

\author{
E J BECKERS, N J REHRER, F BROUNS, F TEN HOOR, \\ AND W H M SARIS \\ From the Department of Human Biology, University of Limburg, Maastricht, The Netherlands
}

SUMMARY In literature several techniques are described for the measurement of gastric emptying. One of these is the double sampling technique of George which has the advantage that it enables multiple measurements of total gastric volume in one experiment. In order to estimate net gastric emptying, however, it is important to differentiate between the test meal volume present in the stomach and gastric secretion.

In the present study George's technique was extended with a calculation procedure to estimate gastric secretion and net test meal outflow. An in vitro experiment was carried out which showed an accuracy of 5-10\% for this method. An in vivo comparison was made with Hunt's chloride technique, which is used for estimating gastric secretion. Sixteen subjects participated in a 60 minute test with water as a test meal. Regression analysis showed a high degree of correlation $\left(R^{2}=0.99\right)$ between Hunt's method and the proposed method. The data obtained indicate that the proposed method gives a reliable estimation of net gastric emptying and is simple to do as no further measurements have to be carried out other than those needed for George's method.

A suitable and widely used technique to measure gastric volume is the double sampling technique described by George. ${ }^{1-3}$ This method depends on the determination of dye concentration in the gastric samples obtained before and after adding a known amount of dye to the stomach contents. Determinations can be repeated as often as needed and each determination is independent. The assumptions made in George's method are that during the procedure complete mixing of dye and gastric contents is obtained, ${ }^{4}$ the amount of dye absorbed or secreted by the stomach during the sampling period is negligible, ${ }^{5}$ no water is absorbed by the stomach, ${ }^{2}$ and gastric emptying does not occur during mixing or sampling or can be corrected for. Correction for the latter might prove difficult, however, and can introduce

Address for correspondence: Dr E J Beckers. Department of Human Biology, University of Limburg. PO Box 616, 6200 MD Maastricht, The Netherlands.

Received for publication 21 June 1988. new inaccuracies as gastric emptying is not a linear process.

A disadvantage of George's method is that it only gives the possibility of measuring the total volume of gastric contents, which in fact consist of gastric secretion, swallowed saliva, and consumed meal. In most experiments, however, it is interesting to differentiate between the volumes of a test meal in the stomach and of gastric juice secreted over a certain period. Hunt ${ }^{6}$ proposed a solution for this problem by measuring not only the concentration of the marker added according to George's method, but also the chloride concentration in the gastric contents. He stated that if the chloride concentration of the gastric juice is constant, the volume of gastric secretion can be calculated and thus also the volume of the test meal. A critical point in Hunt's method is the assumption that the chloride concentration in secreted gastric juice is constant over a longer period and the same for all subjects. Nordgren ${ }^{7}$ and 
Hobsley $^{\star}$ showed that chloride concentration depends on the excretion rate of gastric juice. If the secretion rate rises, chloride concentration rises as well. Furthermore, several authors showed ${ }^{4-12}$ that there is a marked difference in chloride concentration in the gastric secretion between subjects.

In fact there are two rather simple methods to differentiate between meal and gastric juice. One of these methods is adding a second non-absorbable marker to the meal at the start of the experiment. By using one marker for the determination of the total volume (George's method ${ }^{1}$ ) one can calculate the amount of test meal left, based on the dilution of the second marker. This method needs extra measurements which increases the chance of errors. Another disadvantage is that at the end of the experiment the concentration of the second marker might become very low and difficult to measure, because of dilution with gastric secretion. The second is George's extended with a calculation as described below. In this way the total volume of gastric contents and the volume of a liquid test meal can be measured without the need of extra experiments or measurements.

\section{CALCULATION}

The abbreviations used are explained as follows: capital letters represent a variable, $\mathrm{V}$ for volume, $\mathrm{C}$ for concentration, and $\mathrm{A}$ for amount. Raised suffixes are $s$ for gastric contents, $i$ for dye, $t$ for test meal. Lower suffixes are $\mathrm{n}$ for the serial number of the observation, $\mathrm{b}$ for before, and a for after adding the dye. (For a complete list of variables and equations see the addendum.) The theory runs as follows: let the volume of gastric contents at determination number $\mathrm{n}$ before adding dye be $\mathrm{V}_{\mathrm{nb}}^{\mathrm{s}}(\mathrm{ml})$ and the dye concentration in the stomach at that moment $\mathrm{C}_{\mathrm{nh}}^{\mathrm{s}}$ $(\mathrm{mg} / \mathrm{ml})$. After adding a volume $\mathrm{V}_{\mathrm{n}}{ }_{\mathrm{n}}(\mathrm{ml})$ of dye with concentration $C_{n}^{i}(\mathrm{mg} / \mathrm{ml})$, the volume of the gastric contents $\left(\mathrm{V}_{\mathrm{na}}^{\mathrm{s}}\right)$ will be $\mathrm{V}_{\mathrm{nb}}^{\mathrm{s}}+\mathrm{V}_{\mathrm{n}}^{\mathrm{i}}$ and the dye concentration in the stomach at that moment $\mathrm{C}_{\mathrm{na}}^{\mathrm{s}}$. The absolute amount of dye present in the stomach after adding dye is equal to the amount of dye present before adding dye plus the amount of dye added. This results in the equations given by George' (addendum eq 1 and eq 2). If a test is done it will start by giving a test meal with a certain dye concentration, thus in the first determination of a series the volume of dye added $\left(\mathrm{V}_{1}^{\mathrm{i}}\right)$ will be the volume of the test meal given $\left(\mathrm{V}_{1}{ }_{1}\right)$ and $\mathrm{C}_{1}{ }_{1}$ its dye concentration, while $\mathrm{C}_{1 \mathrm{~b}}^{\mathrm{s}}=\mathbf{0}$. In all following determinations $V_{n}^{i}$ is the volume and $C_{n}^{i}$ the concentration of the dye solution added to the gastric contents during the determination. Using the same data as obtained for the first determination of the volume of gastric contents according to George's method, calculation of the amount of test meal left in the stomach at the $\mathrm{n}$-th determination can be done as follows: after the addition of dye solution in the first determination of the volume of gastric contents, the amount of dye in milligrams in the stomach $\left(A_{1 a}\right)$ equals the concentration of dye in the stomach after adding dye multiplied by the volume of the gastric contents at that time (addendum eg 3 ). $A_{1 a}$ is equal to the amount added to the test meal and is thus representative for the volume of the test meal $\left(\mathrm{V}^{\mathrm{t}}{ }_{1}\right)$. In the second determination the amount of dye in the stomach before adding dye solution is $\mathrm{A}_{2 \mathrm{~b}}$ milligrams (addendum eq 4). The ratio of $A_{2 b}$ over $A_{1 a}$ represents the fraction of $A_{1 a}$ still present in the stomach at the second determination. As $A_{1 a}$ is equal to the amount of dye in the test meal, the volume of the test meal which is still present in the stomach at the second determination of gastric contents, $\mathrm{V}_{2}{ }_{2}$, can be calculated from this ratio of $A_{2 b}$ over $A_{1 a}$ (addendum eq 5). Similarly the ratio of $A_{3 b}$ over $A_{2 a}$ represents the fraction of $A_{2 a}$ still present in the stomach at the third determination of the volume of gastric contents. As $A_{2 a}$ is equal to the amount of dye in the stomach after adding dye in the second determination, while the volume of test meal present in these contents is $\mathrm{V}_{2}{ }_{2}$, the volume of the test meal still present in the stomach at the third determination $\left(\mathrm{V}_{3}{ }_{3}\right)$ can be calculated by combining these factors (addendum eq 6 ). This yields the following general formula:

$$
V_{n}^{t}=\frac{A_{n b}}{A_{(n-1) a}} \cdot \frac{A_{(n-1) b}}{A_{(n-2) a}} \cdots \frac{A_{2 b}}{A_{1 a}} \cdot V_{1}^{t}
$$

Where $\mathrm{V}_{\mathrm{n}}(\mathrm{ml})$ is the volume of the test meal still present in the stomach at the $\mathrm{n}$-th determination of the volume of gastric contents and A $(\mathrm{mg})$ is the amount of dye present in the stomach at a certain moment. The indices $a$ and $b$ denote after and before adding dye respectively and $\mathrm{V}_{1}{ }_{1}(\mathrm{ml})$ is the volume of the original test meal.

It can be seen from equation 1 that the determination of the volume of gastric contents $V^{s}{ }_{n b}$ using the method of George is fully independent of former determinations. It only depends upon the added volume of the dye solution $\left(\mathrm{V}_{\mathrm{n}}^{\mathrm{i}}\right)$, the concentration of this solution $\left(\mathrm{C}_{n}{ }_{n}\right)$ and the dye concentration in the stomach measured before $\left(\mathrm{C}^{\mathrm{s}}{ }_{\mathrm{nb}}\right)$ and after $\left(\mathrm{C}^{\mathrm{s}}{ }_{\mathrm{na}}\right)$ adding the dye respectively. On the contrary, calculation of the volume of the test meal still present in the stomach at the $\mathrm{n}$-th determination of the volume of the gastric contents using equation 3 , is fully dependent upon all determinations of $\mathrm{V}$ and $\mathrm{C}$ made before. Thus one wrong determination will influence all the following ones. 


\section{Methods}

To check this method an in vitro experiment was performed. A test meal of $600 \mathrm{ml}$ water $\left(\mathrm{V}^{\mathrm{t}}{ }_{1}=\mathrm{V}_{1}{ }_{1}\right)$ with a marker (phenol red) concentration of $15 \mathrm{mg} / \mathrm{l}$ $\left(C_{1}{ }_{1}=C_{1}{ }_{1}\right)$ was used. A starting volume of the stomach of $50 \mathrm{ml}\left(\mathrm{V}^{\mathrm{s}}{ }_{1 \mathrm{~b}}\right)$ gastric juice present in the stomach at the onset of the test, an emptying rate of $100 \mathrm{ml}$ and a production rate of $20 \mathrm{ml}$ gastric juice per interval were assumed, resulting in a net emptying rate of 80 $\mathrm{ml}$ per interval. $T_{n b}$ and $T_{n a}$ are the interval times before and after adding $5 \mathrm{ml}$ concentrated phenol red $(500 \mathrm{mg} / \mathrm{l})$ as a marker. Mixing was performed by aspirating and reinjecting the 'stomach contents' with a $50 \mathrm{ml}$ syringe (monoject, cathetertip, nr $1100-$ 560281) for one minute, and during this period a pumping action was performed at least 12 times. Sample taking, adding of 'stomach juice' and withdrawing 'gastric contents' was performed with similar syringes. Phenol red marker was added using a $10 \mathrm{ml}$ Methrom piston burette. $\mathrm{NaCl}$ was added to the original test meal in a concentration of $150 \mathrm{mmol} / \mathrm{l}$ as a second marker. As there will not be any further adding of $\mathrm{NaCl}$, the amount of liquid test meal left in the stomach can be calculated out of the concentration of $\mathrm{NaCl}$ in the samples, the total volume of gastric contents and the initial $\mathrm{NaCl}$ concentration in the test meal according to equation 9 (see addendum). At every interval $\left(T_{n b}\right.$ and $\left.T_{n a}\right)$ a $1 \mathrm{ml}$ sample was taken. To obtain the phenol red concentration an alliquot of every sample was diluted 20 fold with a $\mathrm{NaOH} / \mathrm{NaHCO}_{3}$ buffer (concentration $0 \cdot 25 /$ $0.50 \mathrm{~mol} / \mathrm{l}$ ) and measured using a Bausch and Lomb 1001 spectrophotometer at $560 \mathrm{~nm} .{ }^{5}$ The $\mathrm{NaCl}$ concentration was obtained by measuring the sodium concentration using an IIL 243 flamephotometer. In addition to this the total gastric volume and liquid test meal volume were calculated from the starting volume and the chosen emptying and production rates. To check the method in vivo we conducted a number of experiments, using Hunt's $s^{6}$ modification of George's method as a comparison. Sixteen healthy male volunteers between the age of 18 and 30 with an average body weight of $75 \mathrm{~kg}$ participated in the experiment. Subjects arrived at the laboratory in a fasted state, where a standardised breakfast was administered. A low fat complete nutritional liquid (Meritene ${ }^{\circledR}$ (Wander), 20 energy \% fat, $5 \mathrm{ml} / \mathrm{kg}$ body weight) was chosen since fat is a strong inhibitor of gastric emptying, and particulate matter from solid food could clog the nasogastric tube. A nasogastric tube (silicon, French 14) was placed 75 minutes after breakfast was given, the stomach was washed until no further residue was obtained, and a recovery test was done for control of the positioning of the tube tip. ${ }^{13}$ Two hours after breakfast the test meal (water, $8 \mathrm{ml}$ / $\mathrm{kg}$ body weight, containing $15 \mathrm{mg} / \mathrm{l}$ phenol red) was administered through the tube, mixed with whatever gastric contents, and an initial sample was immediately taken, so that the remaining gastric contents could be accounted for in determining initial dye concentration. Samples were taken at intervals of 10 or 20 minutes according to schedule (Table 1). At every interval a sample was taken, $10 \mathrm{ml}$ of dye $(500$ $\mathrm{mg} / \mathrm{l}$ ) was added and mixed, and then a second sample was taken. Mixing, sample drawing and addition of dye was performed as described in the in vitro experiment. The total amount of sample taken was the same as the amount of phenol red dye added. Using the previously mentioned equations both secretion and volume changes could be calculated. During the whole test subjects were sitting in a chair. Phenol red concentration was measured in the same way as in the in vitro experiment, Chloride was measured conductometrically using an Eppendorf Chloridmeter 6610.

Table 1 In vivo comparison of Hunt's method and proposed method (average of 16 subjects)

\begin{tabular}{|c|c|c|c|c|c|c|}
\hline \multirow{2}{*}{$\begin{array}{l}\text { Time } \\
(\min )\end{array}$} & \multicolumn{2}{|c|}{$\begin{array}{c}V_{\text {nh }}^{\text {nh }} \\
\text { George's method }\end{array}$} & \multicolumn{2}{|c|}{$V_{n}^{t}$} & \multicolumn{2}{|c|}{$\begin{array}{c}V_{n}^{\prime} \\
\text { Proposed method }\end{array}$} \\
\hline & $m l$ & $s d$ & $m l$ & $s d$ & $m l$ & $s d$ \\
\hline 0 & 701 & 98 & 663 & 92 & 598 & 59 \\
\hline 10 & 289 & 136 & 252 & 122 & 222 & 110 \\
\hline 20 & 134 & 79 & 111 & 79 & 90 & 73 \\
\hline 30 & 87 & 64 & 59 & 50 & 40 & 45 \\
\hline 40 & 42 & 56 & 26 & 38 & 18 & 31 \\
\hline 60 & 22 & 36 & 9 & 16 & 5 & 11 \\
\hline
\end{tabular}

Table 2 In vitro evaluation of George's method and proposed method for calculations of test meal volumes

\begin{tabular}{|c|c|c|c|c|c|c|c|}
\hline \multirow[b]{4}{*}{ Interval } & & & \multicolumn{5}{|c|}{ Experimental values } \\
\hline & \multirow{2}{*}{\multicolumn{2}{|c|}{$\begin{array}{l}\text { Theoretical } \\
\text { values }\end{array}$}} & \multirow{2}{*}{\multicolumn{2}{|c|}{ Concentration }} & \multicolumn{3}{|l|}{ Method } \\
\hline & & & & & \multirow{2}{*}{$\frac{\text { George }}{V_{\mathrm{nh}}^{\mathrm{nh}}}$} & \multirow{2}{*}{$\frac{N a C l}{V_{n}^{\prime}}$} & \multirow{2}{*}{$\frac{\text { Proposed }}{V_{n}^{\prime}}$} \\
\hline & $\begin{array}{c}V_{\mathrm{nh}}^{\mathrm{s}} \\
\mathrm{ml}\end{array}$ & $\begin{array}{l}V^{t}{ }_{n} \\
m l\end{array}$ & $\begin{array}{l}p h r^{*} \\
m g / l\end{array}$ & $\begin{array}{c}\mathrm{NaCl} \\
\text { mmolll }\end{array}$ & & & \\
\hline$T_{1 h}$ & 600 & 600 & $15 \cdot(0)$ & $146 \cdot 0$ & 600 & 600 & 600 \\
\hline$T_{1 a}$ & 648 & 599 & $14 \cdot 14$ & $135 \cdot 0$ & 635 & 599 & 587 \\
\hline $\begin{array}{l}T_{2 b} \\
T_{2 a}\end{array}$ & 567 & 507 & $\begin{array}{l}13 \cdot 33 \\
17 \cdot 83\end{array}$ & $129 \cdot 5$ & 536 & 476 & 475 \\
\hline $\begin{array}{l}T_{3 b} \\
T_{3 a}\end{array}$ & 490 & 418 & $\begin{array}{l}16 \cdot 50 \\
21 \cdot 75\end{array}$ & $125 \cdot 0$ & 455 & 374 & 389 \\
\hline $\begin{array}{l}T_{4 b} \\
T_{4 a}\end{array}$ & 413 & 333 & $21 \cdot 00$ & $118 \cdot 5$ & 410 & 326 & 333 \\
\hline $\begin{array}{l}T_{5 b} \\
T_{5 a}\end{array}$ & 336 & 253 & $\begin{array}{l}26 \cdot 08 \\
33 \cdot 69\end{array}$ & $112 \cdot 5$ & 306 & 237 & 236 \\
\hline
\end{tabular}

phr* = phenol red. 


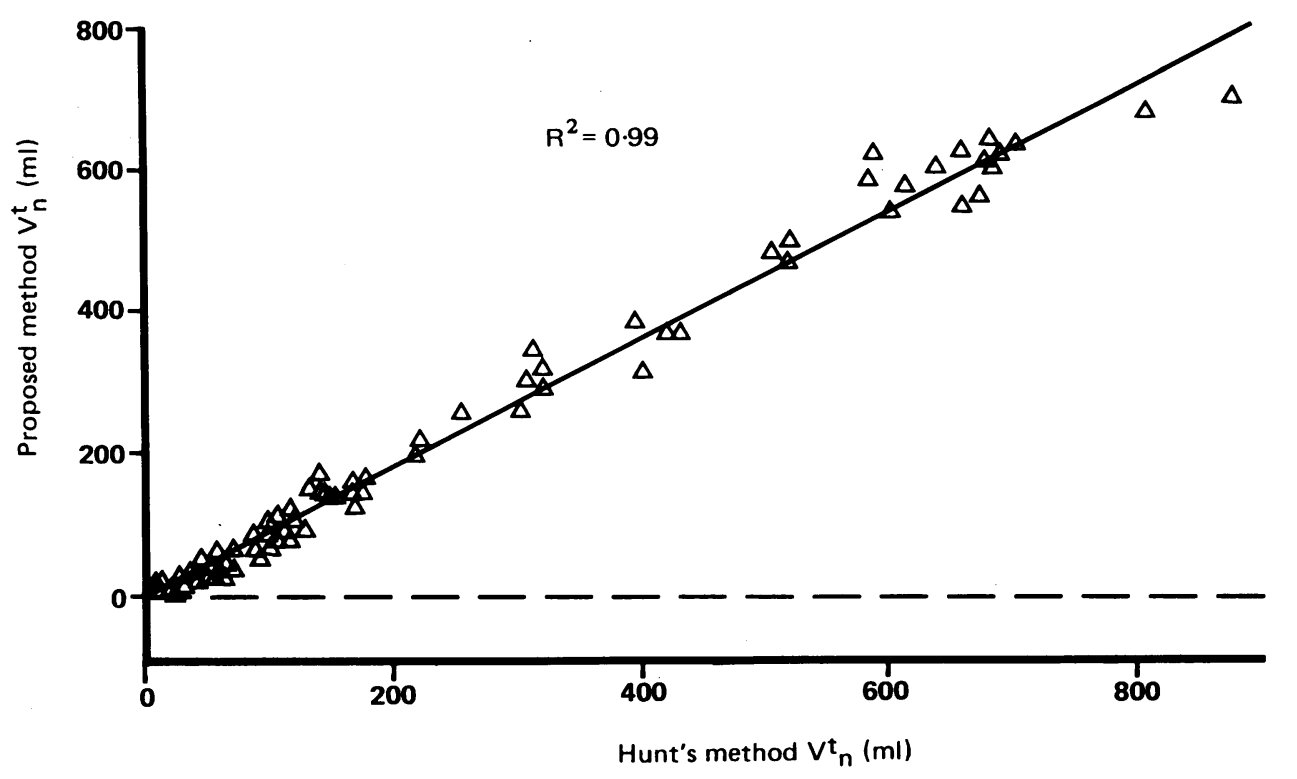

Figure Comparison of Hunt's method and proposed method for the determination of test meal volume $V_{n}{ }_{n}$ in vivo.

\section{Results}

The results of the in vitro experiment are presented in Table 2. These data show that in an in vitro experiment (a) it is possible to measure the volume of a liquid test meal and total gastric contents within an accuracy of $10 \%$, which is in accordance with George,' and (b) adding a second marker and calculating test meal volume from its dilution gives no greater accuracy than calculating test meal volume from one marker only.

The results of the in vivo experiment concerning emptying rate of whole stomach contents, net test meal outflow and gastric secretion are presented in Table 1.

\section{Discussion}

Regression analysis (Figure) of the data of the in vivo experiment shows a high degree of linearity between the proposed method and Hunt's method ${ }^{6}$ but when paired $t$ test was done a significant difference was found for every value of the curve. A possible explanation might be an overestimation of the test meal volumes by Hunt's method. This is suggested by the very first samples taken in the test (see Table 1). The average body weight of the subjects was $75 \mathrm{~kg}$, so an average test meal volume of $600 \mathrm{ml}$ was given (8 $\mathrm{ml} / \mathrm{kg}$ body weight) at the onset of the test. With Hunt's method a starting volume of $663 \mathrm{ml}$ is found, an overestimation of $10 \%$.
We conclude that the results of the proposed method are comparable with those of Hunt's method and may give an even better estimate of the volume of a liquid test meal present at any time in the stomach. Moreover, the proposed method is simple to do as a second marker is not necessary and no further assumptions and measurements are needed other than those for George's method. ${ }^{1-5} 12$

This work has partially been sponsored by Wander Ltd, Berne, Switzerland.

\section{Addendum}

$\mathrm{V}_{\mathrm{nb}}^{\mathrm{s}}$ : volume of gastric contents before adding dye $(\mathrm{ml})$

$\mathrm{V}_{\mathrm{na}}^{\mathrm{s}}$ : volume of gastric contents after adding dye (ml)

$\mathrm{V}_{\mathrm{n}}^{\mathrm{i}}$ : volume of dye added $(\mathrm{ml})$

$\mathrm{V}_{\mathrm{n}}^{\mathrm{t}}$ : volume of test meal $(\mathrm{ml})$

$\mathrm{C}_{\mathrm{nb}}^{\mathrm{s}}$ : dye concentration in gastric contents before adding dye $(\mathrm{mg} / \mathrm{ml})$

$\mathrm{C}^{\mathrm{s}}{ }_{\mathrm{n}}$ : dye concentration in gastric contents after adding dye $(\mathrm{mg} / \mathrm{ml})$

$\mathrm{C}_{\mathrm{n}}^{\mathrm{i}}$ : dye concentration in volume of dye added $(\mathrm{mg} /$ $\mathrm{ml})$

$A_{n b}$ : amount of dye in gastric contents before adding dye ( $\mathrm{mg}$ )

$A_{n a}:$ amount of dye in gastric contents after adding dye (mg) 
Calculation of gastric volume:

$$
\begin{aligned}
& \left(V_{n b}^{s}+V_{n}^{i}\right) \cdot C_{n a}^{s}=V_{n b}^{s} \cdot C_{n b}^{s}+V_{n}^{i} \cdot C_{n}^{i} \\
& V_{n b}^{s}=V_{n}^{i} \cdot \frac{C_{n}^{i}-C_{n a}^{s}}{C_{n a}^{s}-C_{n b}^{s}}
\end{aligned}
$$

Calculation of test meal volume:

$$
\begin{aligned}
A_{1 a} & =V^{s}{ }_{1 a} \cdot C^{s}{ }_{1 a} \\
A_{2 b} & =V^{s}{ }_{2 b} \cdot C^{s}{ }_{2 b} \\
V^{t} & =\frac{A_{2 b}}{A_{1 a}} \cdot V^{t}{ }_{1} \\
V_{3}^{t} & =\frac{A_{3 b}}{A_{2 a}} \cdot V^{t}
\end{aligned}
$$

Combining eq 5 with eq 6 yields

$$
V^{t}=\frac{A_{3 b}}{A_{2 a}} \cdot \frac{A_{2 b}}{A_{1 a}} \cdot V_{1}
$$

or in general:

$$
V_{n}^{t}=\frac{A_{n b}}{A_{(n-1) a}} \cdot \frac{A_{(n-1) b}}{A_{(n-2) a}} \cdots \frac{A_{2 b}}{A_{1 a}} \cdot V_{1}
$$

Calculation of test meal volume out of $\mathrm{NaCl}$ dilution:

$$
\mathrm{V}_{\mathrm{n}}^{\mathrm{t}}=\frac{[\mathrm{NaCl}] \text { sample }}{\text { initial }[\mathrm{NaCl}]} \cdot \mathrm{V}_{\mathrm{nb}}^{\mathrm{s}}
$$

\section{References}

1 George JD. New clinical method for measuring the rate of gastric emptying: the double sampling technique. Gut 1968; 9: 237-42.

2 Bandes J, Hollander F, Glickstein J. The effect of fluid absorption on the dilution indicator technique of gastric analysis. Am J Physiol 1940; 131: 470-82.

3 Hurwitz A. Measuring gastric volumes by dye dilution. Gut 1981; 22: 85-93.

4 Dubois A, Castell D. Esophageal and gastric emptying. CRC Press, Boca Raton, Florida, USA. 1984: 73-84.

5 Schedl PH. Use of polyethylene glycol and phenol red as unabsorbed indicators for intestinal absorption studies in man. Gut 1966; 7: 159.

6 Hunt JN. A modification to the method of George for studying gastric emptying. Gut 1974; 17: 812-3.

7 Nordgren B. The rate of secretion and electrolyte content of normal gastric juice. Acta Physiol Scand [suppl] 1963; 58: 1 .

8 Hobsley M, Silen W. The relation between the rate of production of gastric juice and its electrolyte concentrations. Clin Sci 1970; 39: 61.

9 Makhlouf GM, McManus JPA, Card WI. A quantitative statement of 2 component hypothesis of gastric secretion. Gastroenterology 1966; 51: 149.

10 Gardham JRC, Hobsley M. Electrolytes of alkaline human gastric juice. Clin Sci 1970; 39: 77.

11 Hobsley M. Pyloric reflux-modification of 2 component hypothesis of gastric secretion. Clin Sci 1974; 47: 131 .

12 Hollander F, Glickstein J. Secretory studies in whole stomachs. J Dig Dis 1940; 9: 386-91.

13 Hassan MA, Hobsley M. Positioning of subject and of nasogastric tube during a gastric secretion study. Br Med J 1970; i: 458-60. 